\title{
Effects of Temperature on Dynamic Properties of a Biodegradable Polymer Made from Corn Starch*
}

\author{
Masahiro NISHIDA**, Noriomi ITO**, Hiroyuki KAWASE** \\ and Koichi TANAKA** \\ ** Graduate School of Engineering, Nagoya Institute of Technology \\ Gokiso-cho, Showa-ku, Nagoya 466-8555, Japan \\ E-mail: nishida.masahiro@nitech.ac.jp
}

\begin{abstract}
The effect of strain rate on compressive properties of starch-based biodegradable plastics (Nihon Cornstarch Co., CPR-M2) was examined. Dynamic stress-strain curves of starch-based biodegradable plastics were measured over a wide range of strain rates from $10^{-5} \mathrm{~s}^{-1}$ to $10^{4} \mathrm{~s}^{-1}$, using a quasi-static compression testing machine and a split Hopkinson pressure bar (SHPB) system. The strain rate slightly affected Young's modulus and considerably increased 7\% flow stress. Empirical equation for $7 \%$ flow stress was derived for the strain rates from $10^{-5} \mathrm{~s}^{-1}$ to $10^{4} \mathrm{~s}^{-1}$. In addition, the effect of temperature on Young's modulus and flow stress was also examined in a range from $4{ }^{\circ} \mathrm{C}$ to $63^{\circ} \mathrm{C}$. A master curve of $7 \%$ flow stress, reduced to $24{ }^{\circ} \mathrm{C}$, was made. The values of activation energies related to the $\alpha$ and $\beta$ relaxation processes were respectively estimated from the master curve of $7 \%$ flow stress and from the best fit of equations based on Ree-Eyring theory and Bauwens' treatment. Temperature measurement of specimens was also made using thermocouples during dynamic compression.
\end{abstract}

Key words: Compressive Properties, Biodegradable Plastics, Split-Hopkinson Pressure Bar, Strain Rate, Yield Stress, Temperature

\section{Introduction}

In the past several decades, in order to stop the ongoing destruction of the global environment caused by the use of plastic products, investigations into biodegradable plastics, that will decompose in the natural environment and reduce pollution, and biomass plastics (plant-derived plastics) are carried out, and new biodegradable plastics and biomass plastics are continuously developed. There are also many studies on their application to industrial products. In the earliest stages of development, most of the biodegradable plastics were brittle and there were numerous difficulties in the molding processes. Recently, their mechanical properties and impact resistances have been improved by polymer blends or natural fiber reinforcing ${ }^{(1-3)}$. However, in most cases, the impact resistances are based only on the experimental results of Izod impact strength test/Charpy impact strength test and Dynatup impact test ${ }^{(4-6)}$. The basic mechanical properties of biodegradable plastics with respect to the impact resistances are still unknown. Especially, the basic mechanical properties of the impact resistances when temperature changed have not yet been fully elucidated.

In the present study, the strain rate dependency of the stress-strain curves was measured by a universal testing machine and a split-Hopkinson pressure bar system. The effects of temperature on Young's modulus and 7\% flow stress were also examined.

*Received 22 Aug., 2008 (No. 08-0591) [DOI: 10.1299/jmmp.3.287] 


\section{Experimental Methods}

Biodegradable plastics are mainly made with microbial synthesis materials, plant-derived materials and petroleum-derived materials. Because starch-based plastics show good biodegradability in soil, they are used as products for agricultural use, e.g. attractive ropes and mulch film sheets. In addition, because starch-based plastics show good impact resistance and good material workability, they are also used as cushioning peanuts.

In the present study, we used starch-based biodegradable plastics (Japan Corn Starch Co., Ltd.), Cornpole CPR-M2. The biodegradable plastic we used were made with corn starch and show good compatibility with other biodegradable plastics. Their properties taken from the manufacturer data are shown in Table 1. In addition, the tensile properties previously measured by the present authors ${ }^{(7)}$ are also shown in Table 2 . The average values of Young's modulus, yield tensile stress and total elongation of five tensile tests are listed in this table.

Compressive test specimens were made using injection molding, and their end faces were then polished and parallelized. A photograph of a specimen is shown in Fig. 1. Based on the results of the tensile tests, we used compressive test specimens with a diameter of approximately $15 \mathrm{~mm}$, so that stress-strain curves could be accurately measured using our equipment. Specimens' thickness was $5 \mathrm{~mm}$. In the static tests, specimens with the slenderness ratios of 1.5-2.0 should be used ${ }^{(8)}$. However, even in the static tests, we used specimens of the same size as those in the dynamic tests, for preparation reasons. Based on previous research it is expected that, due to friction effects, the stress of our specimens with a small slenderness ratio, 0.33 , will be approximately $4-6 \%$ larger than that of specimens with slenderness ratios of 1.5-2.0.

In the quasi-static compressive tests of strain rates from $10^{-5}$ to $10^{-1} \mathrm{~s}^{-1}$, we mainly used a universal testing machine (Mori Kikai Seisakusho Co.). At high strain rates of $10^{2}$ to $10^{4}$ $\mathrm{s}^{-1}$, compressive properties were examined by the split Hopkinson pressure bar shown in Fig. 2. The input and output bars were made of aluminum alloy A2024, and their diameter and length were $28 \mathrm{~mm}$ and $1500 \mathrm{~mm}$, respectively. Strain gages were put on both sides of an input bar $735 \mathrm{~mm}$ away from the specimen and an output bar $400 \mathrm{~mm}$ away from the specimen. We placed silicone grease lubricant between the bars and specimens to reduce the frictional restraint. Because the stress histories were almost the same on both ends of specimens, the stress and strain of specimens were calculated from the strain of bars measured by the strain gages based on the following equations ${ }^{(9)}$ :

$$
\begin{aligned}
& \sigma(t)=\frac{A E}{A_{S}} \varepsilon_{T}(t) \\
& \varepsilon(t)=\frac{2 c_{3}}{L} \int_{0}^{t}\left[\varepsilon_{I}(t)-\varepsilon_{T}(t)\right] d t
\end{aligned}
$$

where $\varepsilon_{I}$ and $\varepsilon_{T}$ are the axial strain in the input bar induced by the incident wave and the axial strain in the output bar induced by the transmitted wave. $E$ and $c_{3}$ are Young's modulus and elastic wave velocity of the input and output bars, respectively. $L$ is the specimen thickness. $A$ and $A_{S}$ are the areas of cross sections of the input/output bars and the specimens. Material constants of the aluminum alloy (A2024) bars we used in the calculation are shown in Table 3. We used brass strikers with a diameter of $20 \mathrm{~mm}$ and

Table 1. Properties of biodegradable plastic, Cornpole CPR-M2, taken from the data of manufacturer.

Density $1.5 \mathrm{~g} / \mathrm{cm}^{3}$

Glass transition temperature

Heat deflection temperature

$70^{\circ} \mathrm{C}$

Izod impact strength test Specific heat

Flexural modulus

$80^{\circ} \mathrm{C}$

$5 \mathrm{~kg} \cdot \mathrm{cm} / \mathrm{cm}^{2}$

$1.27-1.77 \mathrm{~J} / \mathrm{g} /{ }^{\circ} \mathrm{C}$

$1.6 \mathrm{GPa}$

$28.4 \mathrm{MPa}$ 
Table 2. Tensile properties at a strain rate of $1.0 \times 10^{-3} \mathrm{~s}^{-1}$ measured by the present authors.

\begin{tabular}{cr}
\hline Young's modulus & $1.6 \mathrm{GP}$ \\
Yield tensile stress & $23.0 \mathrm{MP}$ \\
Total elongation & $4.5 \%$ \\
\hline & \\
& \\
& \\
& \\
& \\
& \\
& \\
&
\end{tabular}

Figure 1 Photograph of compressive test specimen.

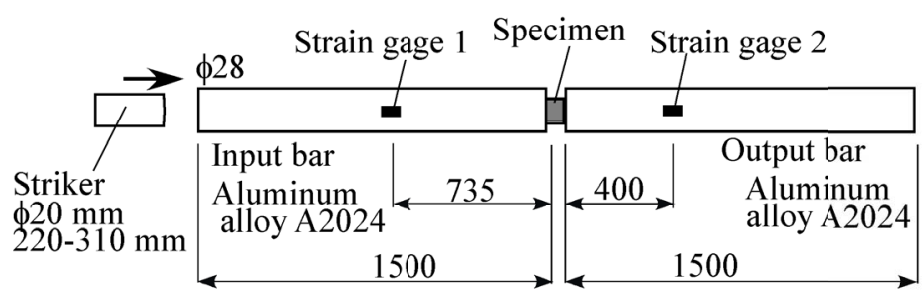

Figure 2 Experimental setup for split Hopkinson pressure bar method.

Table 3. Material constants of input and output bars used in calculation.

\begin{tabular}{ccc}
\hline Density & $\begin{array}{c}\text { Elastic wave velocity } \\
\text { in the bar, } c_{3}\end{array}$ & $\begin{array}{c}\text { Young's modulus } \\
E\end{array}$ \\
\hline $2.78 \times 10^{3} \mathrm{~kg} / \mathrm{m}^{3}$ & $5190 \mathrm{~m} / \mathrm{s}$ & $75 \mathrm{GPa}$ \\
\hline
\end{tabular}

length of 220 to $310 \mathrm{~mm}$. During the experiments, our laboratory was maintained at a temperature of 18 to $25^{\circ} \mathrm{C}$ and at a humidity of 30 to $65 \%$.

\section{Results of Compressive Tests}

At first, the result of a quasi-static compressive test is shown in Fig. 3. The cross head speed of the universal testing machine was $3.5 \mathrm{~mm} / \mathrm{min}$ (strain rate $1.1 \times 10^{-2} \mathrm{~s}^{-1}$, temperature $22{ }^{\circ} \mathrm{C}$, humidity 63\%). First, the stress increased with strain. Second, the nominal stress-strain curve showed a peak in the vicinity of the elastic limit. Third, the stress decreased slightly with strain. The stress remained steady at $37 \mathrm{MPa}$. Young's modulus at a strain rate of $1.1 \times 10^{-2} \mathrm{~s}^{-1}$ was determined to be $0.95 \mathrm{GPa}$ by the collinear approximation of the stress-strain curve below a strain of 0.02 (nominal stress approximately $20 \mathrm{MPa}$ ). Even at the same strain rate, Young's modulus obtained from the compressive test was smaller than that from the tensile test shown in Table 2. Yield stress (the first peak in the vicinity of the elastic limit) or flow stress of the compression test is larger than that of the tensile test because of the hydrostatic pressure and the friction between the bars and specimens.

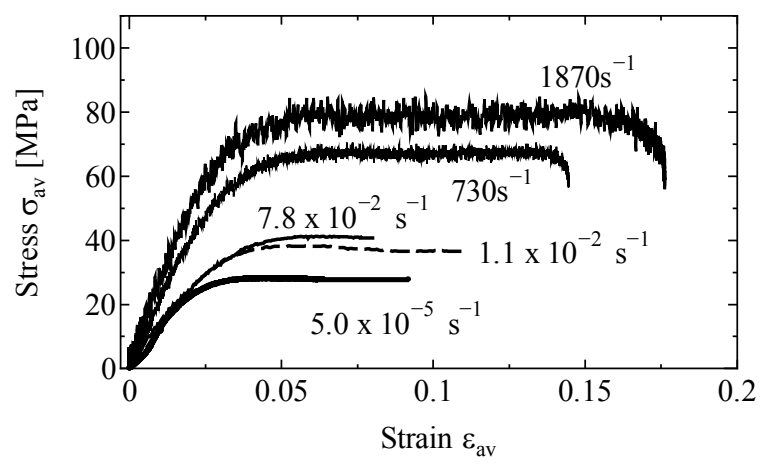

Figure 3 Comparison of stress-strain curves with respect to strain rate. 


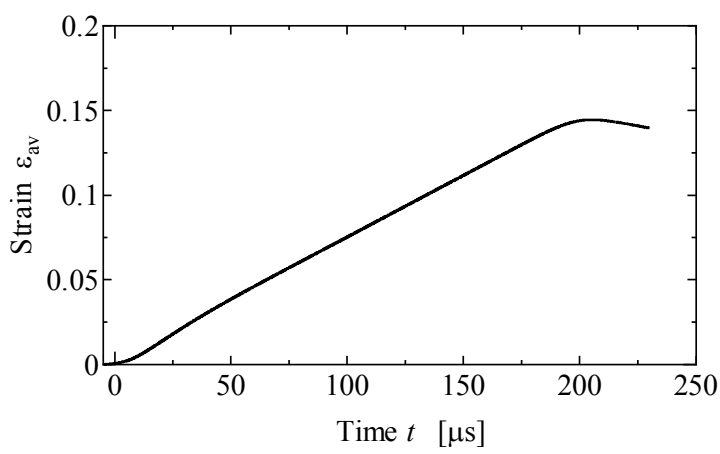

(a) Strain

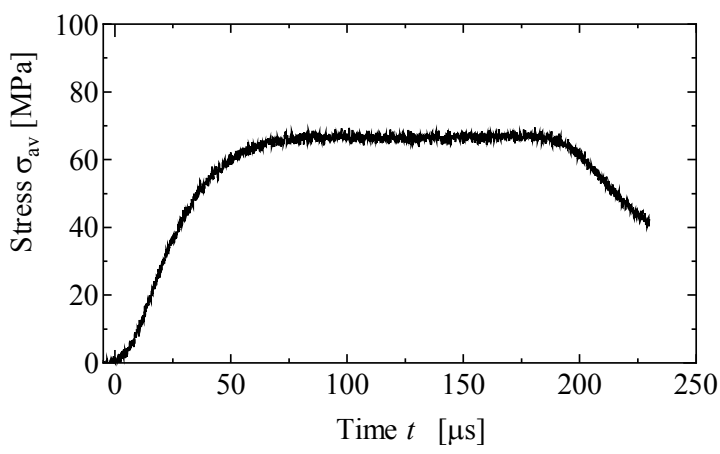

(b) Stress

Figure 4 Stress history and strain history at a strain rate of $730 \mathrm{~s}^{-1}$ (Temperature $25^{\circ} \mathrm{C}$, Humidity $31 \%$ ).

Next, the dynamic properties of the specimen were examined using the split Hopkinson pressure bar method. Figure 4 shows the strain history and stress history of the specimen obtained from the strain gages using Eq. (1) and (2). It was found from the strain history that the strain increased at an increasing rate from 10 to $180 \mu$ s after the onset of the dynamic loading. The strain rate determined by the collinear approximation of the portion was $730 \mathrm{~s}^{-1}$. The stress history increased rapidly up to $60 \mu \mathrm{s}$ after the onset of the dynamic loading. After that, even though the strain increased at an increasing rate, the stress remained steady at approximately $66 \mathrm{MPa}$. The stress started to decrease gradually at 180 $\mu \mathrm{s}$. Therefore, the useful portion of the stress was approximately $170 \mu \mathrm{s}$.

The dynamic stress-strain curve obtained from Fig. 4 (a) and (b) is plotted in Fig. 3. The dynamic stress-strain curve at a strain rate of $1870 \mathrm{~s}^{-1}$ is also shown in Fig. 3. The flow stress and Young's modulus increased with loading rate as is commonly seen in engineering plastics. The stress-strain curve at high strain rates did not show any peaks in the vicinity of the elastic limit. In most of the strain rate, however, when the strain was 0.05 to 0.10 , the flow stress hardly changed with increasing strain. Therefore, we compared the flow stresses at the strain of 0.07 , that is $7 \%$, of the stress-strain curve, as shown in Fig. 5. We added the experimental results of large specimens (diameter $27.8 \mathrm{~mm}$, thickness $10 \mathrm{~mm}$ ) at a temperature of $23 \pm 1{ }^{\circ} \mathrm{C}$ and humidity of $50 \pm 2 \%$, to Fig. 5 . In the present study, $7 \%$ flow stress of all experimental results increased linearly with the loading rate up to a strain rate of $10^{2} \mathrm{~s}^{-1}$. At the strain rate of approximately $10^{2} \mathrm{~s}^{-1}$, the increasing rate of $7 \%$ flow stress changed because of polymer relaxation processes as can be seen in polymethyl methacrylate and polycarbonate. In Fig. 5, the experimental results of specimens of $3.0 \%$ water absorption $^{(7)}$ were compared with those without absorption. Water absorption considerably decreased the flow stress.

We thought that the trend of $7 \%$ flow stress could be described by the following form 
based on the result of Bauwens-Crowet et al. ${ }^{(10)}$ and Aya and Nakayama ${ }^{(11)}$.

$$
\sigma_{\text {flow }}=A \log \dot{\varepsilon}_{a v}+B+C \sinh ^{-1}\left(D \dot{\varepsilon}_{a v}\right)
$$

Here, $A, B, C$ and $D$ are undetermined coefficients. By fitting such undetermined coefficients in Eq. (3) to the experimental results shown in Fig. 5, the following relationships were derived:

$$
\begin{aligned}
& \sigma_{\text {flow }}=5.00 \times \log \dot{\varepsilon}_{a v}+47.0+20.8 \times \sinh ^{-1}\left(5.06 \times 10^{-4} \times \dot{\varepsilon}_{a v}\right) \\
& \sigma_{\text {flow }}=4.90 \times \log \dot{\varepsilon}_{a v}+29.8+20.8 \times \sinh ^{-1}\left(2.60 \times 10^{-4} \times \dot{\varepsilon}_{a v}\right)
\end{aligned}
$$

Second, we examined the effect of temperature on the stress-strain curves at high strain rates from $10^{2}$ to $10^{4} \mathrm{~s}^{-1}$. We heated up the portions of input and output bars near specimens using two sets of silicone rubber heaters (HEATWELL $\AA$, Kawai Electric Heater Co., Ltd.) of $60 \mathrm{~mm}$ in length. The stress-strain curves of specimens in the strain rate region of 900-1090 s $\mathrm{s}^{-1}$ were shown in Fig. 6. Young's modulus slightly decreased with increasing

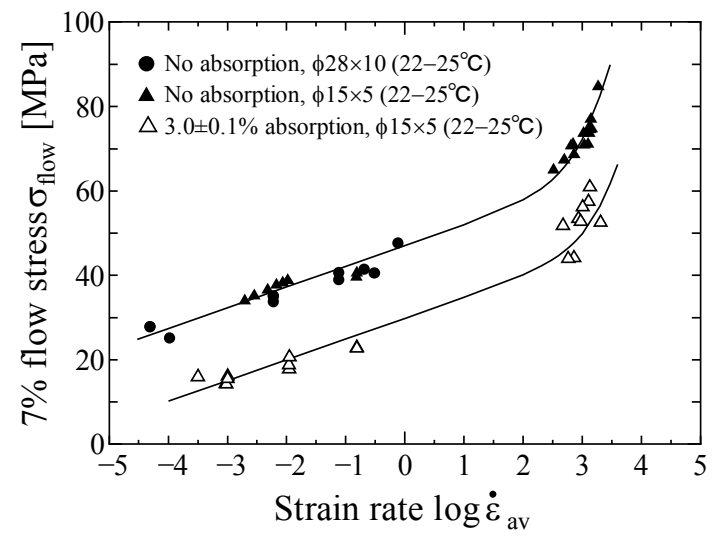

Figure 5 Relationship between 7\% flow stress and strain rate.

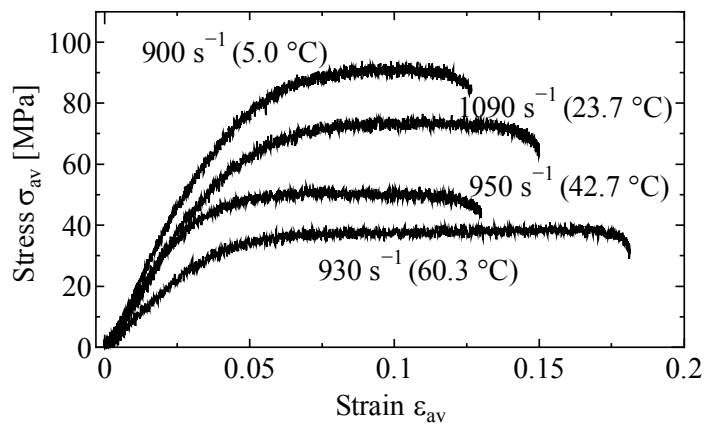

Figure 6 Effect of temperature on stress-strain curves at strain rates of 900-1090 s${ }^{-1}$.

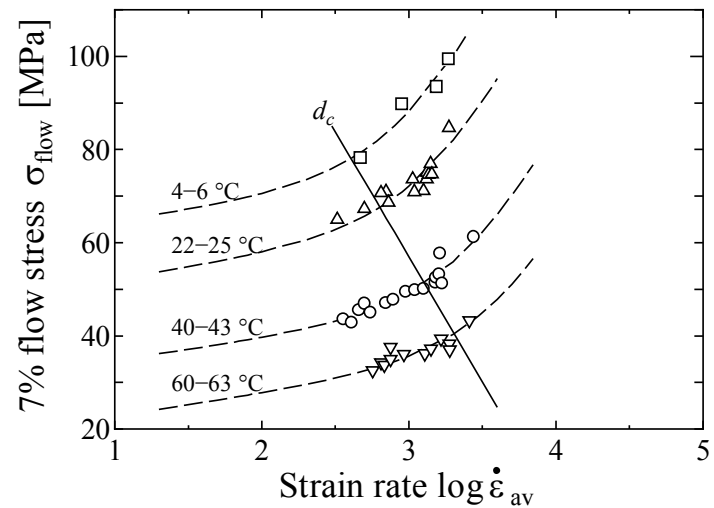

Figure 7 Effect of temperature and strain rate on $7 \%$ flow stress. 


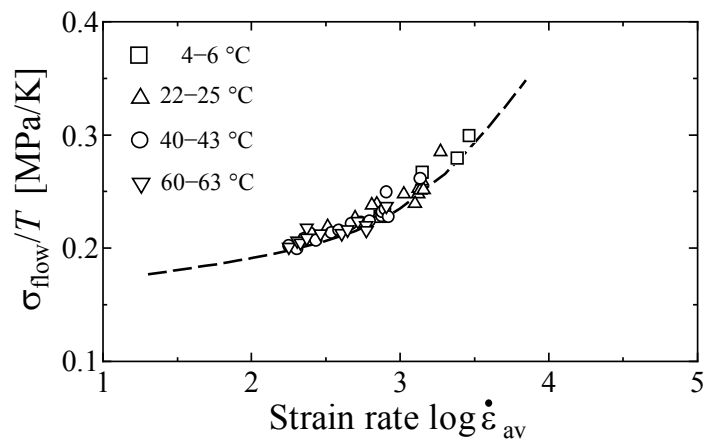

Figure 8 Master compressive flow stress curve reduced to $24{ }^{\circ} \mathrm{C}$. The dashed curve is calculated from the Ree-Eyring Equation (6).

temperature as is commonly seen in most engineering plastics. The $7 \%$ flow stress considerably decreased with increasing temperature.

The temperature dependency of $7 \%$ flow stress in all of the experimental results was examined again and illustrated in Fig. 7. By fitting the undetermined coefficients in Eq. (3) to the experimental results at each temperature, the dashed lines in Fig. 7 were obtained. The 7\% flow stress at each temperature increased with increasing strain rate. The master compressive flow stress curve reduced to $24{ }^{\circ} \mathrm{C}$ was generated by the shift of all curves along a slanting straight line, $d_{\mathrm{c}}$, as drawn in Fig. 8. This result shows that our starch-based biodegradable plastics obey the time-temperature superposition principle.

Bauwens-Crowet et al. ${ }^{(10)}$ showed that the trend of flow stress could be described by the following form based on Ree-Eyring theory as well as Bauwens' treatment:

$$
\frac{\sigma_{\text {flow }}}{T}=A_{c \alpha}\left(\ln 2 C_{\alpha} \dot{\varepsilon}+\frac{Q_{\alpha}}{R T}\right)+A_{c \beta} \sinh ^{-1}\left(C_{\beta} \dot{\varepsilon} \exp \frac{Q_{\beta}}{R T}\right)
$$

Here $A_{c \alpha}$ and $A_{c \beta}[\mathrm{MPa} / \mathrm{K}]$ are constant, $C_{\alpha}$ and $C_{\beta}[\mathrm{s}]$ are constants containing a frequency factor, $Q_{\alpha}$ and $Q_{\beta}[\mathrm{kcal} / \mathrm{mol}]$ are the activation energies related to the $\alpha$ and $\beta$ processes respectively, $T[\mathrm{~K}]$ is absolute temperature, and $R[\mathrm{kcal} /(\mathrm{mol} \bullet \mathrm{K})]$ denotes the universal gas constant.

By fitting the undetermined coefficients in Eq. (6) to the experimental results shown in Fig. 7 and 8 , the values of the parameters are given in Table 4 .

Table 4. Parameters calculated from the fit of Eq. (6) to the data in Fig. 8.

\begin{tabular}{cccc}
\hline$\alpha$ process & \multicolumn{3}{c}{$\beta$ process } \\
\hline$Q_{\alpha}$ & $73.6 \mathrm{kcal} / \mathrm{mol}$ & $Q_{\beta}$ & $5.4 \mathrm{kcal} / \mathrm{mol}$ \\
$C_{\alpha}$ & $3 \times 10^{-46} \mathrm{sec}$ & $C_{\beta}$ & $4.9 \times 10^{-8} \mathrm{sec}$ \\
$A_{c \alpha}$ & $7.47 \times 10^{-3} \mathrm{MPa} / \mathrm{K}$ & $A_{c \beta}$ & $6.99 \times 10^{-2} \mathrm{MPa} / \mathrm{K}$ \\
\hline
\end{tabular}

Finally, we measured the temperature of specimen during compressive loading using a thermocouple (K-type, Omega Engineering, Inc.) put on the lateral side of specimen. In addition, the evolution of temperature of specimen was also measured by infrared thermography (TH9100MR/WR, NEC Avio Infrared Technologies Co., Ltd.). Figure 9 shows a result of temperature history measured by thermocouple at a strain rate of $1330 \mathrm{~s}^{-1}$. After the onset of the dynamic loading, temperature ranged from $24.0^{\circ} \mathrm{C}$ to $27.3{ }^{\circ} \mathrm{C}(+3.3$ ${ }^{\circ} \mathrm{C}$ ). Figure 10 shows photographs recorded by infrared thermography. They show that temperature increased approximately $2.6^{\circ} \mathrm{C}$ due to dynamic compression. The evolution in temperature of our starch-based biodegradable plastics was very small under the conditions adopted in the present work. Rittel ${ }^{(12)}$ investigated the thermomechanical behavior of polycarbonate using the total ratio, $\beta_{\text {int }}$ of the mechanical energy converted into heat. When 
we calculate the ratio using temperature evolution $\left(+3.3{ }^{\circ} \mathrm{C}\right)$, the parameters in Table 1 and stress-strain curve shown in Fig. 11, we obtained $\beta_{\text {int }}=0.53-0.74$. In other words, half or more of the mechanical energy converted into heat at a strain rate of $1330 \mathrm{~s}^{-1}$, and our experimental condition was between the adiabatic condition and isothermal condition.

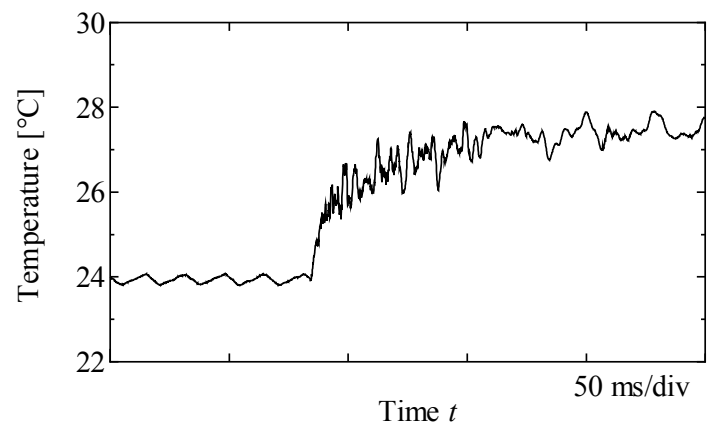

Figure 9 Temperature history of specimen measured by thermocouple at a strain rate of $1330 \mathrm{~s}^{-1}$.

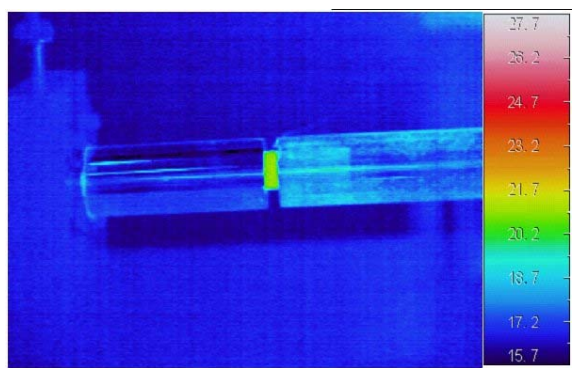

(a) Before dynamic compression

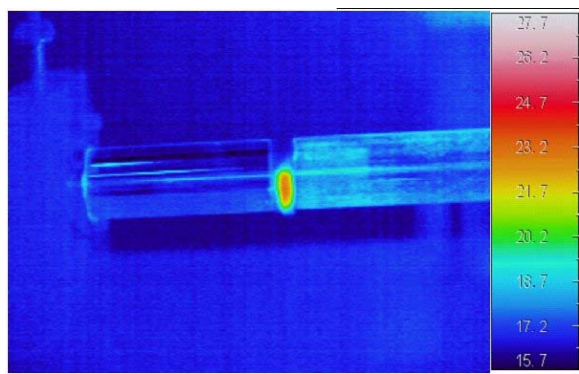

(b) After dynamic compression

Figure 10 Photographs recorded by infrared thermography.

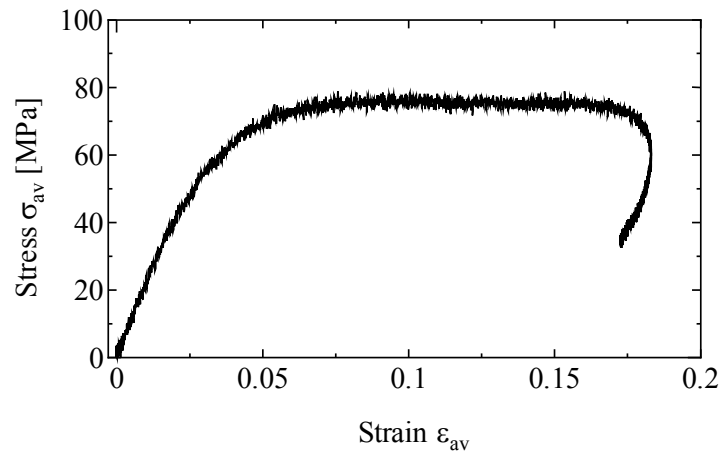

Figure 11 Stress-strain curves at a strain rate of $1330 \mathrm{~s}^{-1}$. 


\section{Conclusions}

We examined the effect of temperature on the stress-strain curves using our split Hopkinson pressure bar system. We showed the relationship between 7\% flow stress and the logarithm of the strain rate. Parameters with respect to the activation energies related to the $\alpha$ and $\beta$ processes could be obtained by Ree-Eyring theory, Bauwens' treatment and curvefitting technique. The evolution of specimens' temperature was small even though the strain rate was high. From the calculated total ratio of mechanical energy into thermal energy, our experimental condition was between the adiabatic and the isothermal condition.

\section{Acknowledgments}

The authors are greatly indebted to Dr. K. Ogawa of Space Dynamics Laboratory, LLC, in Japan for his valuable advice with respect to the thermally activated process concept.

\section{References}

(1) Wollerdorfer, M., and Bader, H., Influence of Natural Fibres on the Mechanical Properties of Biodegradable Polymers, Industrial Crops and Product, Vol. 8 (1998), pp. 105-112.

(2) Yoon, J.S., Oh, S.H., Kim, M.N., Chin I.J., and Kim, Y.H., Thermal and Mechanical Properties of Poly(L-lactic acid)-Poly(ethylene-co-vinyl acetate) Blends, Polymer, Vol. 40 (1999), pp. 2303-2312.

(3) Rosa, D.S., Guedes, C.G.F., and Bardi, M.A.G., Evaluation of Thermal, Mechanical and Morphological Properties of PCL/CA and PCL/CA/PE-g-GMA Blends, Polymer Testing, Vol. 26 (2007), pp. 209-215.

(4) Tams, J., Joziasse, C.A.P., Bos, R.R.M., and Rozema, F.R., High-impact Poly(L/Dlactide) for Fracture Fixation: In Vitro Degradation and Animal Pilot Study, Biomaterials, Vol. 16 (1995), pp. 1409-1415.

(5) Thakare, I.M., Desai, S., Sarawade, B.D., and Devi, S., Studies on Biodegradability, Morphology and Thermo-mechanical Properties of LDPE/modified Starch Blends, European Polymer Journal, Vol. 37 (2001), pp. 151-160.

(6) Johnson, R.M., Tucker, N., and Barnes, S., Impact Performance of Miscanthus/ Novamont Mater-Bi Biocomposites, Polymer Testing, Vol. 22 (2003), pp. 209-215.

(7) Nishida, M., Tanaka, K., and Ito, N., Effects of Loading Rate and Water Absorption on Compressive Properties of Starch-Based Biodegradable Plastics, Multi-phases and Multi-components Materials Under Dynamic Loading, (2007), pp. 401-408, IPPT PAN.

(8) ASTM E9-89a, Annual book of ASTM Standards, Vol. 03.01, American Society for Testing and Materials, (1995), p. 101.

(9) Gray G.T. III, Classic Split-Hopkinson Pressure Bar Testing, ASM International, Vol. 8 (2000), pp. 462-476.

(10) Bauwens-Crowet, C., Bauwens J.C., and Homes G., Tensile Yield-Stress Behavior of Glassy Polymers, Journal of Polymer Science, Vol. 2, No. 7 (1969), pp. 735-742.

(11) Aya, T., and Nakayama, T., Influence of Strain Rate on Yield Stress of Polymers, $J$. Japan Society for Technology of Plasticity, Vol. 40 (1999), pp. 596-600.

(12) Rittel, D., On the Conversion of Plastic Work to Heat During High Strain Rate Deformation of Glassy Polymers, Mechanics of Materials, Vol. 31 (1999), pp. $131-139$. 